\title{
METACOGNITIVE STRATEGY FOR VOCABULARY LEARNING
}

\author{
Jamaris \\ Dosen pada Sekolah Tinggi Ilmu Tarbiyah (STIT) Payakumbuh
}

\begin{abstract}
This article proposed some important issues relating with teaching English vocabulary. This article also quoted various literature that have a correaltion with teaching English vocabulary for Indonesian students who were not from English Department. Specially, this article discussed about some issues relating with teaching strategy (Metacognitive strategy) and its procedure in teaching English vocabulary to the students. At last, this article might give a recommendation for those students in improving their English vocabulary.
\end{abstract}

Key Words: metacognitive strategy, vocabulary learning

\section{INTRODUCTION}

I n Indonesia, the teaching of English is the Teaching of English as a foreign language (TEFL). TEFL, itself is instructed starting from primary school levels up to universities. It spends about twelve years for learners in Indonesia for learning English. Honestly, it is a sufficient time for them to make them capable to use English both in spoken and written languages. Again, in colleges or universities the students learn English again and again. Some of them choose English study program, and some others take different departments.

Consciously or not, the teaching English for non-English study programme students is just a compulsary subject which should be taken during studying at a college or university. The teaching program is dominantly how to comprehend reading texts concerning with their minor program. Suppose an education study program student takes the English subject, he or she will learn English for two credits or two time fourty-five minutes per week during one semester. much about new information on education. During learning English They read some passages, translate them into Indonesian, and then memorize the new words in both English and Indonesian. Students are instructed to be able to translate a passage from Indonesian into English or vice versa. They to were also trained to find the meanings of the new words in a bilingual dictionary almost without guidance, they often missed the right definitions. So, at that time, vocabulary was their biggest obstacle in learning English. They could remember the new words for only a short period of time and when they were in translation mode. When a different mode was used, e.g., giving the English definition, they mostly forgot the words they have learned in the translation mode.

Surprisingly, when they learned English in private courses for high school students a few years ago and asked your students about their reasons of taking private lessons, the answers were quite similar to my own experience. One common reason was "I 
cannot do my reading assignments". The actual problems that I found were that they did not know the meaning of many words in their reading texts, they could not do the translation tasks given by their teachers, and therefore could not answer the reading comprehension, questions. The private students problems made us think that there might be something trouble with the formal classroom vocabulary learning. How did it come?

However, this is a big case of all foreign language classroom settings in Indonesia. You may say that maybe it is time to look at classroom foreign languagevlearning and see whether we do have the problem of classroom foreign language instruction, especially vocabulary learning.

Vocabulary is knowledge of words and word meanings. However, vocabulary is more complex than this definition. First, words come in two forms: oral and print. Oral vocabulary includes those words that we recognize and use in listening and speaking. Print vocabulary includes those words that we recognize and use in reading and writing. Second, word knowledge also comes in two forms, receptive and productive. Receptive vocabulary includes words that we recognize when we hear or see them. Productive vocabulary includes words that we use when we speak or write. Receptive vocabulary is typically larger than productive vocabulary, and may include many words to which we assign some meaning, even if we don't know their full definitions and connotations - or ever use them ourselves as we speak and write. Coady, J. (1997)

Moreover, vocabulary is a knowledge that study about word, part of word that give clues to the meaning of whole words. Vocabulary is a core component of language proficiency and provides much of the basis for how well learner speaks, listen, read, and write. It has been claimed that successful language learners have their own "special ways of learning English vocabulary". The idea can probably help us with both understanding more about the nature of language learning and also to facilitate the language learning process for others. Since this premise, most of the research in the area of language learning strategies has focused on the identification, description, and classification of useful learning strategies. Oxford, R.L. (1994)

Furthermore, there is a list of strategies used by successful foreign language learners, adding that they learn to think in the language and address the affective aspects of language acquisition as well. Learning strategies are as "special thoughts or behaviors that individuals use to comprehend, learn, or retain new information". Ehrman, M., \&. Oxford, R. (1990)

During the eighties to nineties, research mainly focused on categorizing the strategies found in the studies of the previous decade. As a result, several taxonomies were proposed to classify them, including classifications of language learning strategies in general and language sub-skills strategies in particular. Two experts have divided the strategies into three main branches: cognitive, metacognitive, and socioaffective, each of which includes lots of sub-strategies such as rehearsal, organization, summarizing, deducing, and imagery. Chamot, A. U., and O'Malley, J. M. (1992)

On the other hand, there is a more comprehensive model in which six categories, classified into two groups of direct and indirect exist. The direct strategies include memory, cognitive, and compensation while indirect strategies include metacognitive, affective, and social. The social and affective strategies are found less often in foreign language (FL) learning. This 
is, perhaps, because these behaviors are not studied frequently by FL researchers, and because learners are not familiar with paying attention to their own feelings and social relationships as part of the FL learning process. Oxford, R. (1990b)

The cognitive (e.g., translating, analyzing) and metacognitive (e.g., planning, organizing) strategies are often used together, supporting each other. The assumption is that using a combination of strategies often has more impact than single strategies. The distinctions between cognitive and metacognitive strategies are important, partly because they help us to indicate which strategies are the most important in determining the effectiveness of learning. Graham believes that metacognitive strategies, that allow students to plan, control, and evaluate their learning, have the most central role to play in improvement of learning. Anderson, N.J. (2002b)

\section{THE IMPORTANCE OF VOCABULARY IN LANGUAGE LEARNING}

Vocabulary has been studied in research for more than half a century. It is one of the properties that is specific to language that has to be learned. Vocabulary here includes the words (lexical items) and their meanings together with their syntactic categories and subcategories requirements. Some linguists refer to vocabulary using the term lexicon or mental dictionary. Vocabulary is not only a list of words. It is a system embedded in language. It is a part of any language that is, just like grammar, defined by experts in various ways. Fromkin, V., Rodman, R., Collins, P., \& Blair, D. (1996)
In addition to lexicon, learning vocabulary involves the notion of categorizing words in order that they can be stored in the brain. To be organized in the brain, words are categorized into groups. There are various theories on vocabulary organization.. There are four of them, i.e., prototype theory, semantic feature analysis, semantic field analysis and the relational models. These theories show the relation of one word to another. All of these theories have their own strengths and limitations in representing the organization of vocabulary in the brain. However, they could be useful in FL teaching as the basis of vocabulary teaching instruction. Hatch, E., \& Brown, C. (1995).

However, it seems that language lecturers do not give sufficient attention to vocabulary teaching because they think that vocabulary competence does not have to be taught extensively as it is picked up along the way of learning L2. This is correct to some extent, since much vocabulary is learned incidentally. But to achieve maximum results, lecturers should not rely on just incidental vocabulary learning. One reason is that incidental learning takes time and in reality there is always time limit in learning L2. Another reason is revealed that one element of success in learning foreign language vocabulary is the consistent and skillful use of individually congenial strategies rather than the employment of some particular fixed set of strategies". Individual differences are the key word here. Lawson, M. J., \& Hogben, D. 1996.

Learners need to use suitable methods of learning according to their personal learning styles. Moreover, research on vocabulary teaching and learning shows that there is no one best method of vocabulary teaching and learning, and that the success of 
vocabulary learning activities still depends on many factors including the learners levels of proficiency, interests, and goals. To be able to expose our language learners to as many methods as we can is probably wise, since different learners require different ways of learning. One method that is good for one learner might not be good for another. Some learners can learn from the context, some others have to be taught explicitly. Oxford, R. (1996)

In everyday FL teaching, it is common to refer to vocabulary just in reference to the meaning of the words. Many FL learners experience translation as the default method of vocabulary learning. This method, however, has its limitations. First, there is not always one to one correlation between two languages. Take for example the word rice. In Indonesian there are various kinds of rice, each represented by its own lexical item. In English the word 'rice' refers to any kind of rice. There are also many culturally embedded words that it is almost impossible to find their meaning in another language. Second, in the long run, translation slows down the process of acquiring and accessing the target language. Given the FL words, learners have to check their first language (L1) lexicon before they can access the conceptual level or, in other words, FL has to be accessed through. Kroll, J. F., \& de Groot, A. M. B. 1997.

\section{METACOGNITION}

"Metacognition" is one of the latest buzz words in educational psychology, but what exactly is metacognition? The length and abstract nature of the word makes it sound intimidating, yet its not as daunting a concept as it might seem. We engage in metacognitive activities everyday. Metacognition enables us to be successful learners, and has been associated with intelligence. Chamot, A. U., \& O'Malley, J. M. (1986).

Then, metacognition refers to higher order thinking which involves active control over the cognitive processes engaged in learning. Activities such as planning how to approach a given learning task, monitoring comprehension, and evaluating progress toward the completion of a task are metacognitive in nature. Because metacognition plays a critical role in successful learning, it is important to study metacognitive activity and development to determine how students can be taught to better apply their cognitive resources through metacognitive control. Flavell, J. H. (1979).

Moreover, metacognition involves "active monitoring and consequent regulation and orchestration of cognitive process to achieve cognitive goals. It is also included interpretation of ongoing experience, or simply making judgments about what one knows or does not know to accomplish a task, as other features of metacognition. Along with the notions of active and conscious monitoring, regulation, and orchestration of thought process, Flavell believed through repeated use of metacognition, it might in time become automatized. Flavell, J. H. (1976)

"Metacognition" is often simply defined as "thinking about thinking." In actuality, defining metacognition is not that simple. Although the term has been part of the vocabulary of educational psychologists for the last couple of decades, and the concept for as long as humans have been able to reflect on their cognitive experiences, there is much debate over exactly what metacognition is. One reason for this confusion is the fact that there are several terms currently used to describe the same basic phenomenon (e.g., self-regulation, executive control), or an aspect of that 
phenomenon (e.g., meta-memory), and these terms are often used interchangeably in the literature. There are some distinctions between definitions which emphasize the role of executive processes in the overseeing and regulation of cognitive processes. Flavell, J.H. \& Wellman, H.M. (1977).

Another definition states that metacognition consists of both metacognitive knowledge and metacognitive experiences or regulation. Metacognitive knowledge refers to acquired knowledge about cognitive processes, knowledge that can be used to control cognitive processes. Flavell further divides metacognitive knowledge into three categories: knowledge of person variables, task variables and strategy variables. Anderson, N. J. (2002a).

Most of the early investigations of metacognition were descriptive in nature in that they sought to describe general developmental patterns of children's knowledge about memory processes. They were particularly interested in processes concerned with conscious and deliberate storage and retrieval of information. However, as studies moved from descriptive to empirical, the kinds of methodology expanded, the number of studies increased, and the need for a scheme to classify this growing corpus of literature on metacognition arose. Several classification schemes have been used to group, analyze, and evaluate these strategies and even though there are important differences among them, overall, three general categories consistently appear: cognitive monitoring, cognitive regulation, and a combination of both. Chamot, A. U., \& Kupper, L. (1989).

The metacognitive ability to select and use particular strategies in a given context for a specific purpose means that the learner can think and make conscious decisions about the learning process. Learners should be taught not only about learning strategies but also about when to use them and how to use them. Students should be instructed on how to choose the best and most appropriate strategy in a given situation. The next main component of metacognition is monitoring strategy use. By examining and monitoring their use of learning strategies, students have more chances of success in meeting their learning goals. Students should be explicitly taught that once they have selected and begun to use the specific strategies, they need to check periodically whether or not those strategies are effective and being used as intended. For example, when reading, they can use context to guess the meaning of some unknown vocabulary items. To monitor their use of this strategy, they should pause and check to see if the meaning they guessed makes sense in the text and if not, go back and modify or change their strategy. Anderson, J.R. (1985).

Knowing how to use a combination of strategies in an orchestrated fashion is an important metacognitive skill. Research has shown that successful language learners tend to select strategies that work well together in a highly orchestrated way, tailored to the requirements of the language task. In this case, these learners can easily explain the strategies they use and why they employ them. Bachman, L. F., \& Palmer, A. S. (1996).

Certain strategies or clusters of strategies are linked to particular language skills or tasks. For example, FL writing, like L1 writing, benefits from the learning strategies of planning, selfmonitoring, deduction, and substitution. FL speaking demands strategies such as risk-taking, paraphrasing, circumlocution, self-monitoring, and self-evaluation. 
FL listening comprehension gains from strategies of elaboration, inferencing, selective attention, and self-monitoring. Reading comprehension uses strategies like reading aloud, guessing, deduction, and summarizing. Research shows that use of appropriate language learning strategies often results in improved proficiency or achievement overall or in specific skill areas. Nunan, D. (1991).

One of the most important metacognitive strategies is to evaluate effectiveness of strategy use. Selfquestioning, debriefing discussions after strategies practice, learning logs in which students record the results of their learning strategies applications, and checklists of strategies used can be used to allow the student to reflect through the cycle of learning. At this stage of metacognition the whole cycle of planning, selecting, using, monitoring and orchestration of strategies is evaluated. It should be noted that different metacognitive skills interact with each other. The components are not used in a linear fashion. More than one metacognitive process along with cognitive ones may be working during a learning task. Therefore the orchestration of various strategies is a vital component of second language learning in general and vocabulary learning in particular. Allowing learners opportunities to think about and talk about how they combine various strategies facilitates strategy use.

Brown, T. S. \& Perry, F.L. (1991).

The results of the studies on strategy description and categorization have found their implications in language classrooms in helping lecturers accelerate the language learning of their students. If learners are to be in a position to be made aware of different strategies that can assist them in the process of learning, they should be familiar with the strategies that are available. In other words, if students have to make their strategy selection, they have to know about the process of making this selection, because "informed selection of strategies presupposes knowledge of strategies and knowledge of strategies presupposes instruction". It has been suggested that learning strategy instruction may help learners in three ways: firstly, learning strategies instruction can help students to become better learners, secondly, skill in using learning strategies assists them in becoming independent and confident learners, and finally, they become more motivated as they begin to understand the relationship between their use of strategies and success in learning languages. Lecturers who use metacognitive strategy often become enthusiastic about their roles as facilitators of classroom learning. Strategy training makes them more learner oriented and more aware of their students needs. Lecturers also begin to scrutinize how their teaching techniques relate (or fail to relate) to their students' learning strategies and sometimes lecturers choose to alter their instructional patterns as a result of such scrutiny. Chamot, A. U., Barnhardt, S., El Dinary. P.B., \& Robbins, J. (1999)

With regard to vocabulary learning, several studies show that for most adult learners direct vocabulary instruction is beneficial and necessary, due to the fact that students are not able to acquire the mass of vocabulary just by meaningful reading, listening, speaking and writing. Learners can be taught explicitly how to improve their own vocabulary by teaching them appropriate vocabulary learning strategies in contrast to simply letting students learn vocabulary in their own way. In relation to vocabulary learning strategies, it was reported that there were two approaches to vocabulary learning among students: a systematic approach and an unsystematic approach. In systematic approach learners were more organized and 
independent, used extensive records of lexical items, and reviewed words more often. In unsystematic approach, learners were dependent on the course, used minimal or no records of lexical items, and reviewed words little or not at all. Altman, R. (1997).

It is a stated that the importance of context in vocabulary learning, recommended the use of vocabulary learning strategy instruction approach to enhance lexical acquisition: The proponents of this approach (learning strategy instruction) also believe that context is the major source of vocabulary learning but they express some significant reservations about how well students can deal with context on their own. As a result, there is considerable emphasize on teaching specific learning strategies to students so that they can effectively learn from context. Carrell, P.L., Pharis, B.G. \& Liberto, J.C. (1989).

\section{LANGUAGE STRATEGY}

LEARNING

Finding the usefulness of strategy training, some researchers tried to present a model including the steps to be taken by lecturers for this kind of instruction. It was found two approaches in teaching learning strategy, direct (overt in Oxford's model) and embedded Direct training is "learning strategy instruction in which students are informed about the value and purpose of learning strategies". The training is "guidance in the use of learning strategies that is embedded in the task materials but not explicitly defined to the learner as strategy instruction" They added that embedded approach had little effect on learners. The embedded instruction since with this kind of training the learners who were not familiar with cognitive or socio-affective strategies that were available to them, could not use the metacognitive ones and as a result no transfer occurred. As a result, she recommended the use of a more direct approach for the instruction. Chamot, A. U., and O'Malley, J. M. (1992).

Later, there was a project called Cognitive Academic Language Learning Approach (CALLA) provided a useful framework for direct language learning strategies instruction. The sequence of instruction in CALLA approach is a five-phase recursive cycle for introducing, teaching, practicing, evaluating, and applying learning strategies. In this approach, highly explicit instruction in applying strategies to learning tasks is gradually faded so that students can begin to assume greater responsibility in selecting and applying appropriate learning strategies. The cycle repeats as new strategies or new applications are added to students' strategic repertoires. The CALLA model made a distinction between declarative knowledge and procedural knowledge. Declarative knowledge is defined as "A special type of information in long term memory that consists of knowledge about the facts and things that we know. This type of information is stored in terms of propositions, schemata, and propositional networks. It may also be stored in terms of isolated pieces of information temporal strings, and images" whereas, procedural knowledge is the "Knowledge that consists of the things that we know how to do. It underlies the execution of all complex cognitive skills $\breve{S}$ and includes mental activities such as problem solving, language reception and production, and using learning strategies. Juffs, A. 1996.

In order to have a successful and helpful learning strategy instruction 
some requirements must be met by the lecturers. These are summarized into the following principles that she left subject to further investigation: 1) FL teaching strategy training should be based clearly on students' attitudes, beliefs, and stated needs, 2) strategies should be chosen so that they mesh with and support each other and so that they fit the requirements of the language task, the learners' goals, and the learners' style of learning, 3) teaching should, if possible, be integrated into regular FL activities over a long period of time rather than taught as a separate, short intervention, 4) students should have plenty of opportunities for teaching strategy training during language classes. Nevertheless, not all L2 strategy training studies have been successful or conclusive. Some training has been effective in various skill areas but not in others, even within the same study. Therefore the present study was conducted to shed some light on this issue. Considering that different variable of gender, cultural background, motivation, learning style, and attitudes and beliefs may affect strategy use and learning, the present study can add to the previous literature on strategy training. Brown, H. D. (1994).

\section{JUSTIFICATION FOR THE STUDY}

Most of the research in the field of learning strategy instruction has focused on reading strategies as one of the important language skills and on cognitive strategies as one of the main categories of learning strategies. In addition, most of the research on vocabulary learning strategies has focused on cognitive strategies. Due to the importance of metacognitive learning strategies and vocabulary learning, the present study focused on explicit metacognitive strategy instruction and its impact on lexical knowledge improvement of adult EFL students. (Hulstijn, J. (1997)

The importance of metacognitive strategies has been emphasized by stating, "students without metacognitive approaches are essentially learners without direction or opportunity to review their progress, accomplishment, and future directions". Again, developing metacognitive awareness in learners may also lead to the development of stronger cognitive skills and much deeper processing. It results in critical but healthy reflection and evaluation of thinking. In addition, vocabulary knowledge is known to play a key role in the individuals' proficiency in both first and second language. Vocabulary size was shown to be the best predictor of reading comprehension in L1 and FL. Also it has been shown to correlate highly with global assessment of writing quality and with general language proficiency scores. Cohen, A. D., Weaver, S. F., \& Li, T. (1998).

Finally, as it has been suggested that one of the areas that lecturers could help their students in relation to learning strategies could be to familiarize them with different lexical learning strategies, which would lead to more autonomy in students. Moreover, most of the studies in learning strategies have concentrated on identification, description and classification of learning strategies used by language learners. As a result, more attention should be paid to finding whether strategies used by successful students can be taught to unsuccessful students, and if so, what instructional approaches lecturers should use to teach the strategies. Ellis, R. (1995).

\section{TEACHING PROCEDURE}

The vocabulary strategies which were covered in the journal was summarized and taught in the first year non-English students. The instruction 
and use of vocabulary learning strategies continued throughout the course. It is believed that metacognitive strategies are responsible for controlling other strategies and as a result they have good effectiveness for students started from at the beginning until at the end of the course.

The teaching and learning process of metacognitive strategy can be implemented in the following procedures:

1. Preparation: The purpose of this phase was to help students identify the strategies they are already using and to develop their metacognitive awareness of the relationship between their own mental processes and effective learning. In this step the lecturer explained the importance of metacognitive learning strategies and a handout including different metacognitive strategies was distributed to the students. In relation to vocabulary learning, which was the subject of this study, students with the help and guidance of the lecturer set specific goals for mastering the vocabulary from certain chapters in the textbook within a certain time frame, and they planned their time in order to accomplish the task (timemanagement).

2. Presentation: This phase focused on modeling the learning strategy. The lecturer talked about the characteristics, usefulness, and applications of the strategy explicitly and through examples and illustrated his own strategy use through a reading task in relation to unknown vocabularies. Learners were explicitly taught about the variety of strategies to use when they do not know a vocabulary word they encounter in a text and they judge the word to be important to the overall meaning of the text. But more importantly, they received explicit instruction on how to use these strategies. They were told that no single vocabulary learning strategy would work in every case. For example, word analysis strategy (dividing the word into its component morphemes) may work with some words but not with others. Using contextual cues for guessing the meaning of unknown words may be effective in some rich-context cases but not in context-reduced texts. The preparation and planning, the selection of vocabulary learning strategies, monitoring of strategy selection and use, orchestrated use of several strategies, and evaluation of effectiveness of metacognitive strategies for vocabulary learning were illustrated through several examples.

3. Practice: In this phase, students had the opportunity of practicing the learning strategies with an authentic learning task. They were asked to make conscious effort using the metacognitive strategies in combination with vocabulary learning strategies. The students, by the lecturer's assistance practiced monitoring while using multiple strategies available to them. The students became aware of multiple strategies available to them by teaching them, for example, how to use both word analysis and contextual clues to determine the meaning of an unfamiliar word. Students were shown how to recognize when one strategy isn't working and how to move on to another. For example, a student may try to use word cognate to determine the meaning of the word football. But that strategy won't work in this instance The English equivalent of the word Persian Football is soccer. The students need 
to be able to turn to other strategies like using contextual clues to help them understand the meaning of the word.

4. Evaluation: The main purpose of this phase was to provide students with opportunities to evaluate their own success in using learning strategies, thus developing their metacognitive awareness of their own learning processes. Activities used to develop students self-evaluation insights included self-questioning, debriefing discussions after strategies practice, learning $\operatorname{logs}$ in which students recorded the results of their learning strategies applications, checklists of strategies used, and open-ended questionnaires in which students expressed their opinions about the usefulness of particular strategies.

5. Expansion: In this final phase students were encouraged to: a) use the strategies that they found most effective, b) apply these strategies to new contexts, and c) devise their own individual combinations and interpretations of metacognitive learning strategies. They were asked to consider not only vocabulary learning but also other domains of language learning.

As time went by less time was spent on the checking since it was believed that the use of strategies had changed from factual knowledge to procedural and as a result automatic. "A skilled student uses strategies, and with practice the strategies become nearly automatic". However, throughout the semester, in order to sustain students' awareness, they were periodically asked whether they used the strategies and if they had found them useful. The use of strategies was also systematically reinforced by the lecturer. Moreover, in teaching new vocabulary items the lecturer made the students aware of the importance of using metacognitive strategies in combination with vocabulary learning strategies. Students could do this by asking questions about the strategies they used to learn new vocabulary items. (Hoven, D. 1999:88103.)

\section{CONCLUSION}

Based on the discussion above, it can be concluded that the teaching of vocabulary for non-English department students is purposed to make them capable to use English in spoken and written languages especially for comprehending reading texts. Universally, in the sense that learning vocabulary is important for every language learner, however, the way of learning vocabulary is different from one learner to another as well as from one level to another.

Thus, the explicit metacognitive strategy seems able to improve students' vocabulary learning. In other words, the explicit instruction and practice the experimental group received about how to plan their vocabulary learning, set specific goals within a time frame, select the most appropriate vocabulary learning strategy, monitor strategy use, use a combination of strategies, self-testing degree of mastery of the new vocabulary items after meeting the words for the first time, managing their time by devoting some time during their study hours to vocabulary practice, and finally evaluating the whole process, contributed to this improved and expanded lexical knowledge.

Metacognitive and cognitive strategies may overlap in that the same strategy, such as questioning, could be regarded as either a cognitive or a metacognitive strategy depending on 
what the purpose for using that strategy may be. For example, you may use a self-questioning strategy while reading as a means of obtaining knowledge (cognitive), or as a way of monitoring what you have read (metacognitive). Because cognitive and metacognitive strategies are closely intertwined and dependent upon each other, any attempt to examine one without acknowledging the other would not provide an adequate picture.

Knowledge is considered to be metacognitive if it is actively used in a

\section{BIBLIOGRAPHY}

Altman, R. (1997). Oral production of vocabulary: A case study. In J. Coady, \&

T. Huckin, Second language vocabulary acquisi6ion. (pp. 69-97). Cambridge: Cambridge University Press.

Anderson, J.R. (1985). Cognitive Psychology and its implications. 2nd ed. San Francisco. Freeman.

Anderson, N. J. (2002a). The role of metacognition in second language teaching and learning. ERIC Digest. Education Resources Information Center.

Anderson, N.J. (2002b).Using Telescopes, Microscopes, and Kaleidoscopes to Put Metacongnition into Perspective. TESOL Matters, 12 (4), 2002.

Bachman, L. F., \& Palmer, A. S. (1996). Language testing in practice. Oxford: Oxford University Press.

Blyth, C. 1997. A Constructivist Approach to Grammar: Teaching Teachers toTeach Aspect. Modern Language Journal, 81(1): 50-66. strategic manner to ensure that a goal is met. For example, a student may use knowledge in planning how to approach a math exam: "I know that I (person variable) have difficulty with word problems (task variable), so I will answer the computational problems first and save the word problems for last (strategy variable)." Simply possessing knowledge about one's cognitive strengths or weaknesses and the nature of the task without actively utilizing this information to oversee learning is not metacognitive.

Brown, H. D. (1994). Principles of language learning and teaching. 3rd ed. Englewood Cliffs: Prentice Hall.

Brown, T. S. \& Perry, F.L. (1991). A comparison of three learning strategies for ESL vocabulary acquisition. TESOL Quarterly, 25, 655-70.

Carrell, P.L. (1998). Can reading strategies be successfully taught? http://langue.hyper.chubu.ac.jp/jalt /pub/tlt/98/mar/carrell.html

Carrell, P.L., Pharis, B.G. \& Liberto, J.C. (1989). Metacognitive strategy training for ESL reading. TESOL Quarterly, 23, 647-678.

Chamot, A. U., Barnhardt, S., El Dinary. P.B., \& Robbins, J. (1999). The learning strategies handbook. White Plains, NY: Addison Wesley Longman.

Chamot, A. U., \& Kupper, L. (1989). Learning strategies in foreign language instruction. Foreign Language Annals, 22, 13-24. 
Chamot, A. U., \& O'Malley, J. M. (1986). A cognitive academic language learning approach: An ESL content-based curriculum. Wheaton: National Clearinghouse for Bilingual Education.

Chamot, A. U., and O'Malley, J. M. (1992). The cognitive academic language

learning approach: A bridge to the mainstream. In P. A. RichardAmato \& M. A. Snow (Eds.), The multicultural classroom: Readings for content-area lecturers. White Plains: Longman.

Chamot, A. U., \& O'Malley, J. M. (1994). Language learner and learning $\backslash$ strategies. In N. C. Ellis (Ed.), Implicit and explicit learning of languages (pp. 371392). London: Academic.

Coady, J. (1997). L2 vocabulary acquisition through extensive reading. Cambridge: Cambridge University Press. [-13-]

Cohen, A. D., Weaver, S. F., \& Li, T. (1998). The impact of strategicbased instruction on speaking a foreign language. In A. Cohen. Strategies in learning and using a second language (pp. 107-56). London: Longman.

Cottrell, S. (1999). The study skills handbook. London: Macmillan Press.

Chun, D. M., \& Plass, J-L. 1995. Project Cyberbuch: A Hypermedia Approach to CALL. CALL Journal, 4(1): 95-116.

Ehrman, M., \&. Oxford, R. (1990). Adult language learning styles and strategies in an intensive training setting. Modern Language Journal, 74, 311-327.
Ellis, R. (1985). Sources of variability in interlanguage. Applied Linguistics, $6,118-131$.

Ellis, R. (1995). Modified oral input and the acquisition of word meaning. Applied Linguistics, 16, 409-441.

Flavell, J. H. (1976). Metacognitive aspects of problem solving. In L.B. Resnick (Ed.), The nature of intelligence. Hillsdale, NJ: Erlbaum.

Flavell, J. H. (1979). Metacognition and cognitive monitoring. American Psychologist, 34, 906-911.

Flavell, J.H. \& Wellman, H.M. (1977). Metamemory. In R.V. Kail \& J.W. Hagen (Eds.), Perspectives on the development of memory and cognition. Hillsdale, NJ: Erlbaum.

Hatch, E., \& Brown, C. 1995. Vocabulary, Semantics, and Language Education. New York: Cambridge University Press.

Hulstijn, J. (1997). Mnemonic methods in foreign language vocabulary learning:

Theoretical considerations and pedagogical implications. In J. Coady, \& T. Huckin, Second Language Vocabulary Acquisition (pp. 203-224). Cambridge: Cambridge University Press.

Kern, R. G. (1989). Second language reading strategy instruction: Its effects on comprehension and word inference ability. Modern Language Journal, 73, 135-149.

Kluwe, R. (1982). Cognitive knowledge and executive control: Metacognition. In D. R. Griffin (Ed.). Animal mind-human mind (pp. 201-24). New York: SpringerVerlag.

McCarthy, M. (1990). Vocabulary. Oxford: Oxford University Press. 
Naiman, N., Frohlich, M., \& Todesco, A. (1975). The good second language learner. TESL Talk, 6, 58-75.

Nunan, D. (1991). Language learning methodology. London: Prentice Hall International.

O'Malley, J. M., \& Chamot, A. U. (1990). Learning strategies in second language acquisition. Cambridge: Cambridge University Press.

O'Malley, J. M., Chamot, A. U., Stewner-Mazanares, G., Russo, R., \& Kupper, L. (1985). Learning strategies applications with students of English as a second language. TESOL Quarterly, 19, 285-96.

Oxford, R. L. (1989). Use of language learning strategies: A synthesis of studies with implications for strategy training. System, 17, 235247.

Oxford, R. (1990a). Language learning strategies: What every lecturer should know. New York: Newbury House. [-14-].

Oxford, R. (1990b). Styles, strategies, and aptitude: Connections for language learning. In Parry, T.S. and C.W. Stansfield (Eds.) Language aptitude reconsidered. Englewood Cliffs: Prentice Hall Regents.

Oxford, R.L. (1994). Language learning strategies: An updated. Eric Clearinghouse on Languages and Linguistics, (online).

Oxford, R. (1996). Employing a questionnaire to assess the use of language learning strategies.
Applied Language Learning, 7:1\&2, 25-45.

Oxford, R., Crookall, D., Cohen, A., Lavine, R., Nyikos, M., \& Sutter, W. (1990). Strategy training for language learners: Six situational case studies and a training model. Foreign Language Annals, 22, 197-216.

Oxford, R. L., Park-Oh, Y., Ito, S., \& Sumrall, M. (1993). Learning a language by satellite: What influences achievement? System, $21,31-48$.

Parry, K. (1997). Vocabulary and comprehension: Two portraits. In J. Coady, \&

T. Huckin. Second language vocabulary acquisition (pp. 55-68). Cambridge: Cambridge University Press.

Rubin, J. (1975). What the "good language learner" can teach us. TESOL Quarterly, 9, 41-51.

Rubin, J., \& Thompson, I. (1994). How to be a more successful language learner, 2nd ed. Boston: Heinle \& Heinle.

Sanaoui, R. (1995). Adult learners' approaches to learning vocabulary in second language. The Modern Language Journal, 79, 15-28.

Stern, H.H. (1975). What can we learn from the good language learner? Canadian Modern Language Review, 31, 304-318.

Wenden, A. L. (1987). Incorporating learner training in the classroom. In A. L. Wenden, \& J.

Wenden, A. L. (1998). Metacognitive knowledge and language learning. Applied Linguistics, 19, 515-37. 